\title{
Do Social and Economic Policies Influence Health? A Review
}

\author{
Theresa L. Osypuk • Pamela Joshi • \\ Kimberly Geronimo • Dolores Acevedo-Garcia
}

Published online: 1 June 2014

(C) Springer International Publishing AG 2014

\begin{abstract}
Although social and economic policies are not considered part of health services infrastructure, such policies may influence health and disease by altering social determinants of health (SDH). We review social and economic policies in the USA that have measured health outcomes among adults in four domains of SDH including housing and neighborhood, employment, family strengthening/marriage, and income supplementation. The majority of these policies target low-income populations. These social policies rarely consider health as their initial mission or outcomes. When measuring health, the programs document mental health and physical health benefits more than half the time, although some effects fade with time. We also find considerable segregation of program eligibility by gender and family composition. Policy makers should design future social policies to evaluate health outcomes using validated health measures; to target women more broadly across the socioeconomic spectrum; and to consider family caregiving responsibilities, as ignoring them can have unintended health effects.
\end{abstract}

\author{
T. L. Osypuk $(\bowtie)$ \\ Division of Epidemiology and Community Health, University of \\ Minnesota School of Public Health, 1300 Second Street South, \\ Minneapolis, MN 55454, USA \\ e-mail: tosypuk@umn.edu \\ P. Joshi $\cdot$ K. Geronimo $\cdot$ D. Acevedo-Garcia \\ Institute for Child, Youth and Family Policy, Brandeis University, \\ Heller School for Social Policy and Management, 415 South Street, \\ MS035, Waltham, MA 02453, USA \\ P. Joshi \\ e-mail: pamjoshi@brandeis.edu \\ K. Geronimo \\ e-mail: kgeronim@brandeis.edu \\ D. Acevedo-Garcia \\ e-mail: dacevedo@brandeis.edu
}

Keywords Social policy $\cdot$ Economic policy $\cdot$ Social experiments $\cdot$ Health $\cdot$ TANF $\cdot$ Housing $\cdot$ Housing mobility policy $\cdot$ Social determinants of health $\cdot$ Income $\cdot$ Income supplements $\cdot$ Employment $\cdot$ Marriage $\cdot$ Family strengthening

\section{Introduction}

Social determinants of health (SDH) are defined as the everyday circumstances in which we are born, grow, live, work, play, age, and die $[1,2]$. While health care is one social determinant of health, population health may be more reliant on the economic and social conditions that influence health in the first place [3]. Social stratification is defined as the unequal positioning of subgroups of individuals (e.g., men and women, income groups, racial/ethnic groups) within a patterned social hierarchy which influences power, prestige, and access to resources. As a result of social stratification, the distribution of the social determinants of health - and as a result, health vulnerability - is unequal across population subgroups.

Evidence is mounting that social and economic policies may influence health, even if they are not intended to [4, 5], via the social determinants of health. These policies may reinforce or mitigate the health effects of social stratification. Policies can also influence the distribution of social determinants of health across subgroups, to either reinforce or mitigate inequalities.

Policies may influence health directly or indirectly [5]. Health care and public health policies directly target health through, e.g., health services, provision of health insurance, and prevention (e.g., immunization) programs. In contrast, social policies may indirectly influence health by virtue of their influence on social or economic outcomes (including income, education, employment, housing, marriage). Since these social and economic factors are also causes of health, they can then in turn can affect health [6]. The extent to which 
social policies influence health is an empirical question. Unfortunately, until recently, research on social and economic policies has neither included a logic model or design that includes health as a potential outcome, nor measured health outcomes.

Social policies have the potential to mitigate (or exacerbate) health inequalities by differentially distributing social determinants of health to different population subgroups. For example, many social policies in the USA target their programs to low-income populations. According to conventional public policy formation models, policies are designed to alleviate social problems caused by market failures [7, 8]. While policies may have differential impacts on population subgroups, policymakers do not generally evaluate whether policies increase or decrease disparities [9]. If policies cause adverse outcomes, including for vulnerable subgroups, these effects are often framed as unintended [10]. However, it is becoming increasingly important to examine the health effects of all policies (not just health care policies), including attention to how policies shape social stratification and the distribution of SDH $[1,11]$.

This article reviews whether social and economic policies influence adult health by documenting the health impacts achieved by "non-health" social programs that target lowincome populations. We begin by describing four broad categories of social and economic policies that target low-income adults and review their impacts on health. We exclude policies that explicitly target health, health care, or nutrition as the primary goal of their program.

There have been some prior literature reviews conducted on some segments of the policies we review here. Some of these reviews are outdated (published 2004 or earlier, e.g., $[12,13])$, and some had relatively narrow scopes to their findings by focusing on only one policy (e.g., Earned Income Tax Credit, $[12,13])$. We summarize the results of these reviews herein. Our review differs from prior reviews in its broader scope of policies that impact a range of different social determinants of health, in its inclusion of more recent literature, and in our inclusion of rigorous experiments (when such studies are available), as reported in both the academic and grey literature.

We examine the four areas of housing/neighborhoods, employment, marriage/family strengthening, and income supplementation. The specific social or economic policies under consideration include rental housing affordability (Section 8, or Housing Choice Vouchers); employmentrelated direct income assistance (Temporary Assistance for Needy Families, TANF); family strengthening (healthy marriage) initiatives included in welfare policy; and (un-) conditional income supplements and minimum wage policy. Lastly, we discuss the implications of our findings for the future design of social policies to improve population health.

\section{Methods}

We conducted a review of the literature [14] in the four policy domains, to summarize what currently is known about the health effects on adults of social and economic policies. We started with a focus on federally supported, non-health, social or economic programs or policies, targeting low-income populations that had been evaluated with experimental designs (i.e., housing affordability policy; income assistance (TANF); conditional cash transfers; and marriage and family strengthening initiatives). We then expanded the criteria to consider a broader group of social or economic policies that may influence health, which essentially captured other income policies. We restrict our review to evidence from the USA; for initial evaluations published after 1994; for outcomes among adults including physical health, mental health, substance use/health behavior (including fertility and sexual behavior); and health care insurance, access, or utilization. When policies were evaluated with experimental designs, or were summarized by literature reviews, we prioritized and discussed that evidence. If there was a broader evidence base beyond experiments or literature reviews, we included studies that evaluated an intervention or policy with strong methods using concurrent comparison groups across time (e.g., experimental; difference in difference; regression discontinuity; or pre-post designs).

We cite evaluation reports that have been published (e.g., in the grey literature), but when available, give preference to peer-reviewed journal articles on an intervention or policy. Notably, since the grey literature includes many governmentfunded evaluations with strong (often random allocation) designs, exclusive focus on peer reviewed articles would omit many strong policy evaluations with potential to influence health [13].

We adopted a multifaceted search strategy. We drew on expert knowledge of social policy evaluation; we searched the web sites of federal evaluation sponsors, including Department of Health \& Human Services (DHHS) Assistant Secretary of Planning and Evaluation; DHHS Administration of Children and Families, Office of Planning, Research and Evaluation; Department of Housing and Urban Development (HUD) Policy Development and Research; as well as federal contractor websites that were hired to conduct evaluations (i.e., MDRC, Mathematica, RTI). We searched Pubmed, and both the Cochrane (http://www.thecochranelibrary.com/view/ 0/index.html) and the Campbell (http://www. campbellcollaboration.org/lib/) online libraries; and we reviewed the references cited by included articles.

We excluded studies that were explicitly health policies (e.g., health insurance provision of Medicare or Medicaid; income policies targeting disabled, mentally ill, or aging populations such as Supplemental Security Income (SSI); or home visitation programs). Although in-kind benefits are 
one dimension of the US means-tested social protection system, we excluded studies examining Supplemental Nutrition Assistance Program (SNAP, formerly known as Food Stamps) and WIC (Women, Infants and Children) nutritional supplements, because of their focus on the health-related pathway of nutrition, since our objective is to focus on policies that did not explicitly include health components. We additionally excluded non-health policies outside of the realm of social and economic policy, such as transportation/road design, agriculture/food, physical housing structures (like housing refurbishment), or water/sanitation (although some of these are treated in a recent umbrella review [15]). Although we searched on education policies, we found that no rigorous studies had measured health outcomes in this domain to treat it comprehensively. Although social policies may (and have) influenced the health of children (e.g., Head Start), due to the different outcomes used to operationalize child health, including developmental and educational outcomes, programs that target children are outside the scope of this review.

Beneficial health effects of the policies we reviewed are summarized in Table 1.

\section{Results: Policy Overviews and Health Impacts}

Housing and Neighborhoods

\section{Housing Voucher Subsidies and Housing Mobility Policy}

Rent subsidies are the primary form of federal housing assistance for low-income households [16]. Formerly known as the Section 8 program, and officially currently named the Housing Choice Voucher (HCV) program, it provides qualified low-income participants a government subsidy to assist in paying rent for private housing units. In addition to helping with affordability, voucher-based rental assistance may provide access to better-quality housing units, and may help families rent in higher-quality neighborhoods, including higher income neighborhoods (termed housing mobility) [17]. Thus, housing voucher policy may influence health by increasing income, or via improvements in housing and neighborhood quality [18].

The health effects of offering housing vouchers have been evaluated in several social experiments targeting low income families, HIV positive homeless (or at risk of homelessness) populations, and homeless veterans with psychiatric and/or substance use problems. These programs provided various wrap-around services, including counselling about housing choices and case management services. There has also been one systematic literature review [19], and one other literature review [20]. The Acevedo-Garcia et al., systematic review summarized the early MTO evidence on health and the evidence from other non-experimental housing policies [19]. The Lindberg et al., review summarized rental policies as one of many neighborhood-level housing policies (concluding, notably, that the HCV Program had sufficient evidence for implementation or expansion) [20]. Here we summarize the short and long term MTO findings, as well as reviewing a broader range of experimental housing voucher studies.

Moving to Opportunity for Fair Housing Demonstration Program (MTO). Sponsored by the U.S. Department of Housing and Urban Development (HUD), MTO used a randomized controlled trial (RCT) to provide Section 8 vouchers to families interested in moving out of public housing in five cities $[21,22]$. Families with children under 18 years of age, recruited from public housing in high-poverty neighborhoods were eligible to enroll between 1994 and 1998 [22]. The sample was very low-income and households were predominantly (97\%) female-headed [23].

Over 4,600 families were randomly assigned to one of three treatment groups: (1) the "Regular Section 8" treatment group was offered a housing voucher to subsidize apartment rental; (2) the "Low-Poverty Neighborhood Section 8" treatment group was also offered a housing voucher, but only if it was used to rent an apartment located in a low-poverty neighborhood; this group also received housing counselling to help their relocation; (3) the control group received no further assistance but could remain in public housing. There were two cross-site evaluations after 4-7 years [24] and after 10-15 years $[25 \bullet \bullet]$, as well as several short-term (1-3 year) sitespecific evaluations [26].

In low-poverty neighborhood MTO treatment group families, exposure to neighborhood poverty was substantially reduced, even after 15 years, compared to public-housing controls [23, 24]. Notably, the MTO treatment did not have an effect on any of the primary outcomes, including employment, earnings, education, or public assistance. However, the main outcomes affected by MTO seemed to have been health, in particular mental health. Yet health effects were not uniformly beneficial, with many null findings. Health was measured by self-reported measures, as well as by biomarkers at the final evaluation $[24,25 \bullet \cdot$.

The MTO evaluations found overall that MTO benefited the mental health of the experimental group (mostly female) household heads (psychological distress, major depression, calm/peacefulness, index of mental health). There were some beneficial effects on physical health of (female) adults (e.g., obesity, diabetes, functional limitations/disability, and inflammation) and a suggestion of an adverse effect on substance abuse for adults $[23,24,25 \bullet \cdot, 27]$. These results are summarized in Table 1.

Veterans (HUD-VASH Study). HUD and the Department of Veterans Affairs Supported Housing Program was an RCT 


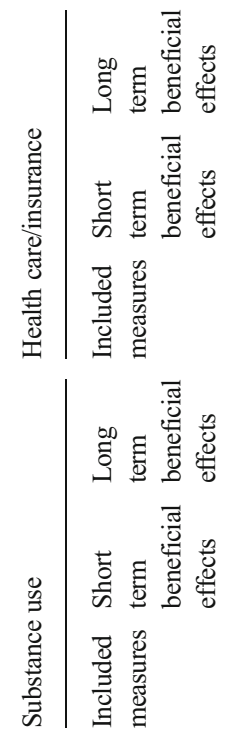

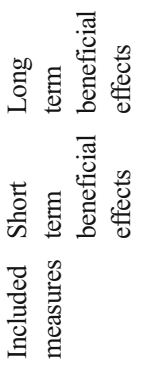

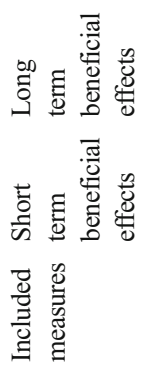

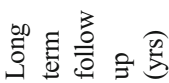

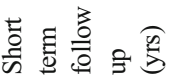

$>>>>>$

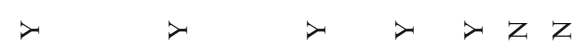

$\frac{n}{0} \quad n \quad 1, n$

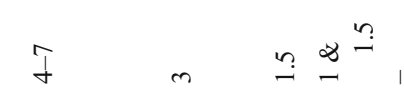

$\ddot{\overrightarrow{\bar{n}}}$

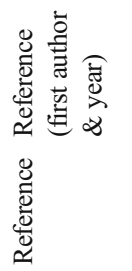

的

ồ

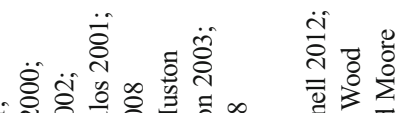

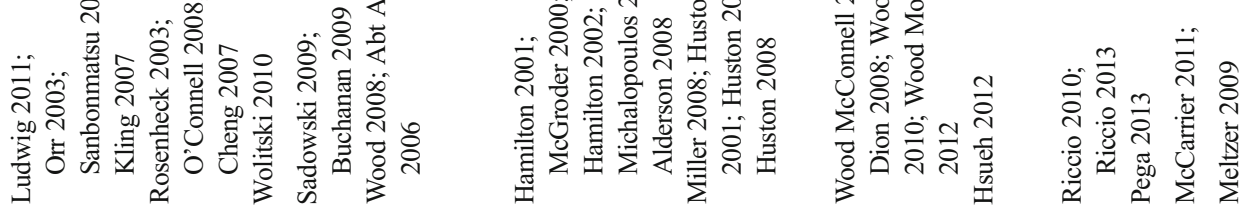

i

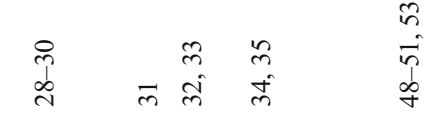

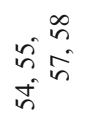

$\frac{1}{6}$

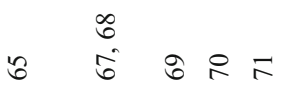

กิ

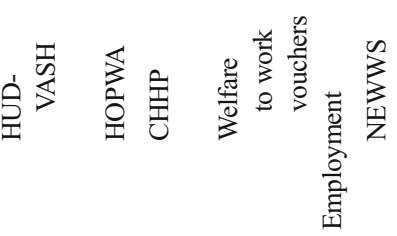

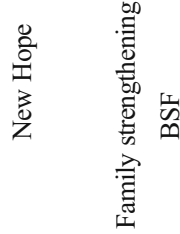

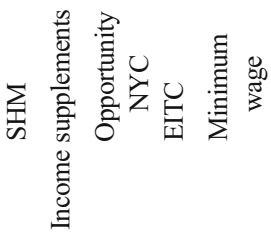




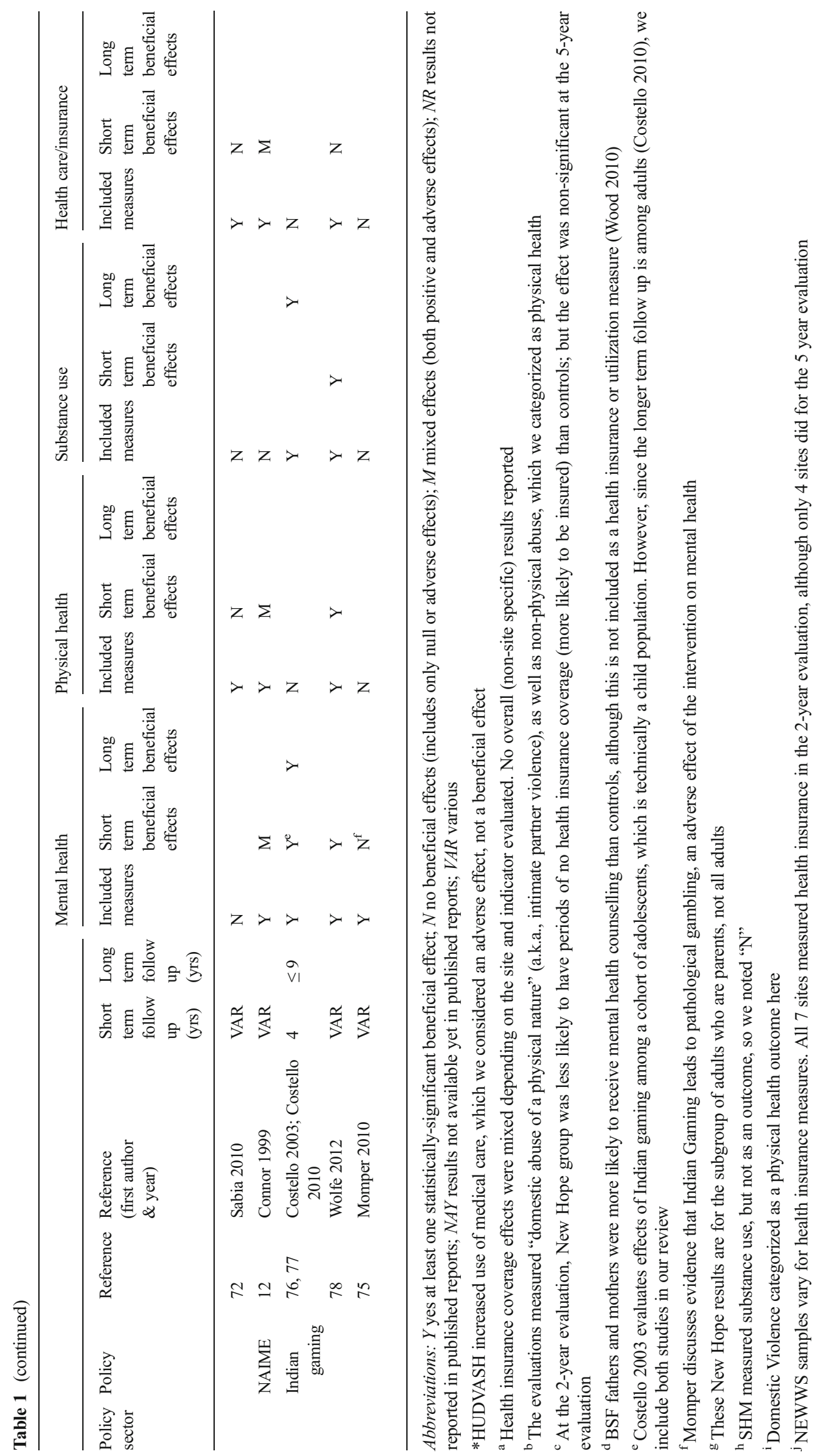


enrolling predominantly male (96 \%) participants between 1992 and 1995; eligible participants could not live with any children. This program tested the effects of a Section 8 housing voucher among homeless/unstably housed veterans who were clinically diagnosed with psychiatric and substance abuse disorders or both. One treatment group received a voucher and housing counselling, case management, and health care referrals; another treatment group received case management and health care referrals; and the control group received the usual care from the Veterans Administration.

VASH significantly reduced the risk of housing loss, and had a positive influence on several measures of addiction, substance use, institutionalization, and quality of life. However, there were no effects on physical health [28-30].

Housing Homeless HIV/AIDS Patients: HOPWA and CHHP. The Housing Opportunities for Persons with AIDS (HOPWA) Housing and Health Study (71\% male) [31], and the Chicago Housing for Health Partnership (CHHP) Study (74 \% male) [32, 33], both used an RCT design to evaluate the effects of Section 8 vouchers on low-income HIV/AIDSdiagnosed patients who were homeless or at risk of homelessness. The HOPWA Study tested the offer of a Section 8 Voucher; it began in 2003 at three sites, among HIVseropositive, and homeless (or at risk of homelessness) populations. The treatment group received immediate Section 8 vouchers with case management. The control group did not receive a voucher, but did have access to usual housing services and case management. There were no significant program impacts on hospitalizations, days spent in the hospital, use of medical care, unprotected sex, number of sex partners or HIV physiological indicators (viral load, CD4 counts, or opportunistic infections) [31]. There were positive impacts on the mental health of the treatment group, including perceived depression and stress.

The CHHP program was also an RCT targeting the homeless population with chronic illnesses including HIV/AIDS. It was conducted in two Chicago-based hospitals between 2003 and 2006. The treatment group received case management and transitional housing followed by stable housing. Case managers helped participants obtain housing and medical care, including referrals for participants with substance abuse or mental health problems. The control group received usual hospital discharge services (no additional follow up or housing assistance). Evaluations found significantly lower rates of hospital days, hospitalizations, and visits to the emergency room for the treatment group for CHHP [32]; and positive impacts on HIV viral loads, undetectable viral load, and living with intact immunity after one year [33].

Effects of Housing Vouchers on Welfare Families (Formerly $W t W$ Vouchers- $W t W V$ ). This study was conducted among welfare to work (WtW) populations from 1999 to 2006 [34].
This RCT randomly allocated Section 8 vouchers among families, primarily female household-heads ( $92 \%$ ) with children who were receiving, eligible to receive, or had recently received Temporary Assistance for Needy Families (TANF) at six sites. The treatment group received a Section 8 voucher plus social services, housing search services, and more intense employment assistance. Control group participants had access to usual TANF services. There was no effect of the program on: receiving employer-provided health benefits; health insurance coverage; affordability of needed medical care or (separately) dental care; current smoking; worry/anxiety; hours of sleep; or self-rated health $[34,35]$.

\section{Urban Renewal}

Urban renewal projects, also called neighborhood renewal, urban regeneration, place-based initiatives, or comprehensive community initiatives, direct large scale investment to address urban neighborhood deprivation across multiple domains of SDH, including income, employment, education, and housing. The comprehensive nature of many place-based initiatives makes it difficult to evaluate this type of initiative [36, 37]. A recent USA-based literature review discussed the potential of ten neighborhood-focused housing or urban planning programs/policies to improve health. Of these, rental voucher policies had sufficient evidence to indicate improved health. Two other policies required more field evaluation but were promising: HOPE VI public housing demolition (which was not evaluated with a comparison group); and Housing Choice Vouchers to relocate to low poverty neighborhoods (note that the voucher policies were discussed above). The remaining seven policies had limited evidence of health effects, with the authors recommending formative research. These seven policies included: universal design; crime prevention via environmental designs; residential siting away from highways; zoning; density bonuses; and green space [20]. Several other literature reviews of evaluations of urban renewal program effects on health have been published describing evidence outside the USA [38, 39], including rehousing and retrofitting interventions in the context of area-based neighborhood renewal [40].

\section{Employment: Welfare to Work and Wage Subsidies}

Originally designed in the 1930s for economically vulnerable widowed mothers, welfare assistance, known as Aid to Families with Dependent Children (AFDC), originated as an income support program, with little attention to parental employment. In response to increasing welfare caseloads and concerns about long-term welfare dependency, the Family Support Act of 1988 mandated the states to provide work supports and impose work requirements through the creation of Job Opportunities and Basic Skills (JOBS) programs. 
Further advancing employment-based strategies, and responding to a policy mandate to devolve federal program administration and design to the states, in 1996 the Personal Responsibility and Work Opportunity Reconciliation Act (PROWRA) changed AFDC, a federal entitlement, to TANF (Temporary Assistance for Needy Families), a block grant program. TANF mandated a work-first approach, requiring that recipients look for work or participate in employment and training activities, addressed work disincentives (by allowing recipients to keep more income from employment), timelimited the benefits to a maximum of five years, and used sanctions to enforce behavioral rules. The states can design their own programs within these new rules, which results in significant variations in program requirements.

Despite the potential role that health status plays in parents' ability to make the transition from welfare to work, there has been limited attention to health assessment and services within the TANF program and the research evaluation studies. Most demonstration projects and evaluation studies are mandated to collect data on income, employment and poverty using administrative records, do not focus in detail on health impacts, and collect limited self-reported health outcomes [41]. Observational studies have documented an association between mental health issues and employment challenges [42], and concluded that mental health conditions are significantly more prevalent among the TANF population than among the general population [43]. Also, welfare recipients face limitations in access to and affordability of mental health services [44]. Non-experimental studies suggest that welfare reform reduced health insurance coverage and service utilization, especially among vulnerable groups such as Hispanic single women and single mothers with low education [45], but that welfare reform did not affect health outcomes [46]. Although welfare reform program alternatives were evaluated with some RCT designs, access to health services and the health impacts of many employment-focused intervention approaches targeting the welfare population are not well understood in the RCT studies. This presents a design challenge for policymakers wishing to decrease health barriers to employment and improve families' economic self-sufficiency and well-being.

\section{National Evaluation of Welfare-to-Work Strategies (NEWWS)}

The evaluation of the JOBS Program (later renamed to the NEWWS study) integrated the findings from RCTs of 11 different mandatory state welfare-to-work program models that served AFDC clients in the early 1990s prior to the 1996 welfare reform in seven geographic locations. Each of the 11 programs varied in its approach to employment assistance, emphasizing either "work first" (known as immediate labor force attachment- LFA), or "human capital investment" (known as basic education and skills acquisition- ESA). Welfare recipients or applicants were recruited to the study sample between 1991 and 1994, randomly assigned to treatment or control group (approximate $\mathrm{N}=57,000$ ), and followed for five years. The treatment group was required to participate in the LFA or ESA components of JOBS programs as a condition of receiving cash assistance, and the control group was not mandated to participate. Administrative records (not including health) were analyzed for all study participants, whereas surveys were administered to selected sites (approximately one quarter of participants) [47].

Overall, the NEWWS evaluation concluded that the LFA approach produced greater economic impacts than the human capital approach, which influenced PROWRA's work first mandate. NEWWS investigated a small number of health outcomes but only in a subset of sites (four sites/seven programs) [48]. The results showed an initial decline in health insurance coverage for the treatment group compared to controls up to two years after random assignment, but no impact in coverage up to five years later [48]. On average there are no significant impacts on depression (CES-D) at two years after random assignment although there was a significant increase for the treatment group compared to controls at one site after two years [49].

Treatment group participants at three sites reported that they were significantly less likely to experience physical domestic abuse during the prior year compared to controls at the five-year evaluation, although effects were non-significant for broader definitions of domestic abuse (including nonphysical abuse) [48]. The study measured one fertility outcome (presence of a new baby), which exhibited non-significant treatment-control differences at all sites $[48,50]$. While there were no overall impacts on depressive symptoms, depression moderated earnings impacts such that positive effects of the program on earnings were larger for the least depressed participants, and smaller for the most depressed, suggesting that addressing mental health could further increase the economic gains made in welfare-to-work programs [51].

In the Next Generation Project, researchers examined welfare-to-work on child and parental outcomes by pooling the results from NEWWS study sites with other RCT evaluations of state welfare-to-work experiments (Connecticut, Florida and Minnesota), the New Hope program, and the Canadian Self-Sufficiency Project (SSP) [52]. Studies reported no significant differences between intervention groups on adult depressive symptoms, although depression again moderated the economic impacts in the SSP [51]. Some new subgroup findings emerged including higher risk of depression among the most disadvantaged mothers compared to moderately disadvantaged mothers [53].

\section{New Hope}

Designed to make work pay for low-income families, the New Hope Demonstration Project in Milwaukee, Wisconsin, 
provided a set of work supports including wage subsidies and subsidized health insurance and child care. Unlike NEWWS, New Hope was not mandatory. Participants did not have to receive welfare nor have children, but were required to live in one of two high poverty neighborhoods, work at least 30 hours per week, and meet income requirements. A communitybased organization provided three years of intensive services during the period of 1994 to 1998. During the course of the research study, health issues were identified as barriers to work; therefore health measures were added to assessments, although the service mix did not change [54].

New Hope included an experimental evaluation of 1,300 participants randomly assigned to either a treatment group, which received New Hope benefits, or a control group, which did not. Approximately $72 \%$ of the full sample were women, and $90 \%$ of the parent sample were mothers. Treatment group members had access to case management and other employment assistance to facilitate job searches if they were unemployed, working less than 30 hours/week, or wanted to switch jobs $[55,56]$. Evaluations were conducted at two years (Y2), five years (Y5), and eight years (Y8) after random assignment, although only a few health outcomes were measured for a subset of parents. Results showed positive or null health effects across all three waves, with no significant health effects at year eight. The New Hope program benefited parents' health insurance coverage (Y2), self-reported physical health (Y5), depression (Y5), and psychosocial measures including stress (Y2) and hope about achieving goals (Y2). There were no effects on psychosocial measures of self-esteem or financial worry $[55,57,58]$.

\section{Welfare Policy - Family Strengthening Initiatives}

Based on the growth of childbearing outside of marriage and the increasing AFDC caseloads, PRWORA not only reformed welfare, but also introduced weak incentives for states to serve two-parent families and reduce out-of-wedlock births [59]. Reauthorizing the TANF program in 2005, the Deficit Reduction Act (DRA) significantly increased funding for local organizations to provide family strengthening activities and fatherhood programs. Although funded by welfare dollars, programs were not required to serve only low-income families, but were mandated to develop domestic violence screening assessments and referrals [60].

\section{Building Strong Families (BSF) and Supporting Healthy Marriages (SHM)}

When the DRA passed in 2005, there was limited research documenting the effectiveness of family-strengthening programs specifically targeting low-income families. Therefore, the U.S. Department of Health and Human Services launched three demonstration programs with accompanying rigorous evaluations, only two of which used an experimental design and included any health measures: Building Strong Families (BSF) and Supporting Healthy Marriages (SHM).

BSF and SHM programs both offered a high dosage of family strengthening education and service coordination to unmarried but romantically involved parents and married parents respectively. All participants across eight sites were low income. Using an RCT design, the BSF evaluation included approximately 4,700 couples and was evaluated at 15 and 36 months. The SHM evaluation included over 6,000 couples and was evaluated at 12 and 30 months. The primary outcomes were measures of relationship quality and stability. Secondary outcomes included intimate partner violence (IPV), psychological well-being, alcohol use, drug use and self-rated physical health.

BSF did not significantly impact adults on primary relationship outcomes or most health variables (including most measures of IPV) at either interim or three-year evaluations $[61,62]$, averaged across sites. One concerning finding is an adverse impact on mothers' experience of more than one severe assault in the treatment group, compared to the control group, at three years [63]. In terms of (secondary) mental and physical health, there was a positive impact on depressive symptoms (CES-D scale) for mothers and fathers at the evaluation midpoint [64], but there was no significant difference at the final evaluation [62]. Other health effects, such as negative impacts on father's physical health, and no impact on alcohol or drug use at 15 months, were not reported in the 36-month evaluation.

On the other hand SHM, which served married parents, did show positive impacts at the first (15 month) evaluation point. Results are not yet available for the 30-month assessment. At 15 months, the SHM treatment was associated with better relationship quality, lower domestic violence (adapted Revised Conflict Tactics Scale), and lower psychological distress (K6 scale), compared to controls. There was little site variation. Some subgroups showed effects; for example, Hispanic couples and individuals experiencing higher marital distress at baseline had larger positive impacts [65॰].

\section{Income Support Policies}

\section{Conditional Cash Transfers}

Conditional cash transfer (CCT) programs incentivize lowincome families to receive cash transfers if they build up their human capital (investing in education, health, nutrition, and preventive health care services), with the goal of preventing future poverty for themselves and their children. These programs have spread quickly throughout the world to over 30 developing nations, after having been introduced in Brazil and Mexico in 1997 [66]. Since CCTs do not provide participants explicit health services (they only incentivize participants to 
receive such services), we have included them in our review even though they may be conceived of as a hybrid type of program since they do require health, preventive health care, and educational investments be made, before families can receive the cash transfer.

Opportunity NYC - Family Rewards Demonstration. The Opportunity NYC Demonstration is a conditional cash transfer program in New York City, the first in a developed nation. The program offers cash assistance to low-income families conditional upon meeting human capital goals to reduce poverty. Introduced in 2007, it randomly assigned low-income families in six of New York City's highest-poverty communities to the treatment group or the control group. The treatment group could receive the cash rewards if they met requirements to achieve certain pre-specified activities and outcomes for children's education, families' preventive health care, and parents' employment. The control group could not receive the rewards. The program is being evaluated by MDRC with an RCT of 4,800 families and 11,000 children. Evaluators measured outcomes after 18 months (Interim Evaluation) [67], and 42 months (Final Evaluation) [68・•]. During the three year period, treatment families received approximately US $\$ 8,700$ on average which reduced financial hardship. Although the Interim Evaluation improved some health insurance and medical care receipt outcomes, and parent selfreported health [67], the Rewards program had few effects on health outcomes, substance use (cigarette use), or on use of preventive medical care as of the Final Report. It did improve health insurance coverage, and produced large increases in family receipts of preventive dental care at both evaluation time-points. The program also reduced fertility (Final Evaluation), and improved nutrition (as a measure of hardship) during the program period. Based on these early results, MDRC refined the program, and is fielding a new program in Memphis, TN and Bronx, NY.

Earned Income Tax Credit (EITC). EITC is a means-tested tax credit for low-income populations, and is a conditional income program - conditional on employment. EITC provides up to $7 \%(11 \%)$ of an average income from wages (US $\$ 3,298$ or US\$5,128 in 2012), for families with one or two dependent children, respectively. The credit intervenes on the income (poverty alleviation) and employment social determinants of health among families with working aged adults. Families must be working to qualify for the credit, and they receive the income as a lump sum after submission of annual income taxes. The federal EITC was introduced in 1975, with increases occurring across time (including a large expansion in 1996). Individual states have also introduced and rescinded EITCs over time. Approximately $80 \%$ of eligible individuals claimed the credit in 2012. The EITC has lifted an estimated 3.3 million adults out of poverty, with low administration costs [69•].

A Cochrane Systematic Review was recently published on the health effects of EITC (called "in-work tax credits" outside the USA) on working-aged adults, including non-randomized study designs that were controlled, before-and-after (prepost), or were interrupted time series. The review identified five studies of the EITC nationwide in the USA, among women. All studies tested whether the 1996 expansion in EITC led to health or health behavior changes, and one study identified the effect of EITC also from state EITC changes. The authors found low-quality, methodologically-limited evidence of either, no effect, or mixed effects (of beneficial and non-significant effects), of EITC on adult health. The authors concluded that the current research evidence is insufficient to answer the review question [69•].

The review of five studies found mixed effects of EITC for tobacco use, and evidence of no association for other health outcomes [69•]. The review documented no significant effects for self-rated health, obesity/overweight, mental health (number of bad mental health days in past month), or physical health (bad physical health days in the past 30 days; number of risky biomarkers for inflammation, cardiovascular disease and metabolic disease). Notably, all but one of these five studies attempted to identify the effect of a federal EITC increase (in 1996), two or more years after the EITC increase occurred [69•].

Minimum Wage Laws. Several studies have tested whether state minimum wage policies are associated with health or health-care access, using serial cross sectional analyses of BRFSS [70, 71], or the Survey of Income and Program Participation [72]. In repeated cross sectional (time trend) analyses, McCarrier [70] found a beneficial effect on one measure of health insurance (unmet medical need), but not a second one (lack of health insurance). Meltzer found that decreasing real minimum wage rates across time are associated with an increase in BMI [71]. Others have found no discernible effects of raising minimum wages on low income populations in terms of health insecurity (going without health insurance, or missing a doctor's visit), or food insecurity (insufficient resources to purchase food or eat a balanced meal) [72]. These studies are generally exploiting the vast variability in state minimum wage laws over time. However the evidence overall is weak, given the study designs.

\section{Unconditional Income Supplementation}

North American Income Maintenance Experiments (NAIME). Connor et al., reviewed income supplementation experiments for health outcomes [12], which included the NAIME studies from the late 1960s-1970s, among some other studies (the latter of which had measured no health 
outcomes). NAIME were the first social experiments conducted to evaluate social programs using clinical trial methods [73]. The objective of the NAIME was to determine the effect of a guaranteed minimum income on workforce participation of low-income families, to inform welfare to work policy. The program provided a combination of a minimum income guarantee and a variable tax rate on earned income, and was implemented at five sites.

Summarizing the NAIME evidence, one site found no effects of income supplements on health or medical care (New Jersey/Pennsylvania IME). Other sites found: that women and children reported increases in illness (Rural IME); there were scattered and inconsistent effects on psychological wellbeing (Rural IME); birth-weight improved in experimental subgroups with two or three risk factors, although there was also a significant decrease in birth-weight in the lowestrisk group (Gary IME); significant birth-weight improvements occurred in some subgroups, but not in others; and the experimental group reported decreased hospital days for men, increased mental health for wives, and decrease in chronic illness duration for female family heads (Seattle/Denver IME) [12]. Although Connor et al., sought to reanalyze the data, many original data files retrieved from storage were unreadable, and/or the health outcome data had not been archived.

Taken together, there were few effects on health and medical care, which were also inconsistent across the four sites; there was substantial subgroup analyses, and most importantly, there were issues with the treatment assignment method (Conlisk-Watts model) that render exposure groups nonexchangeable and therefore causal inference is threatened despite the RCT design [12].

Income Supplements From Gaming Revenues on Indian Reservations. The 1988 Indian Gaming Regulatory Act defined terms for Indian tribes to run legal gaming enterprises on tribal reservations, under sovereign nation status. Nationwide in 2009, 237 Indian tribes in 28 states operated Indian gaming, generating US $\$ 26.3$ billion in gross revenues [74]. Through redistribution of gaming revenues to tribal members, tribal gaming increases household income and alleviates poverty of tribal members [75]. Indian gaming also provides jobs for tribal members, in addition to generating revenues which have been invested to improve reservation infrastructure and fund government services [74].

Several studies have exploited a natural experiment to test the health effects of casinos opening and operating on Indian reservations, via income-poverty alleviation for Native American families, compared to similar non-native American families. One study documented beneficial effects from one Indian reservation (within an ongoing cohort study of children), of casino earnings on adolescent mental health (total, emotional, and behavioral, psychiatric symptoms) [76]; and then on laterlife mental health outcomes in young adulthood (e.g., reduced psychiatric disorders including alcohol and cannabis abuse, dependence, or both), with the youngest Indian cohort, who were exposed to the income supplements the longest, benefitting most [77]. Physical health was not measured. Another study used data from multiple Indian reservations, linked to individual records from BRFSS, applying time series difference-in-difference methods, to document that Indian gaming improves not only income, but also physical health (obesity, overweight, hypertension, diabetes), substance use (smoking, heavy drinking), and mental health (anxiety), although not health care, for Native Americans on those tribal reservations [78]. Momper lastly reviewed evidence that although casinos may improve economic resources for tribal members, tribal casinos also increase problem or pathological gambling of Native Americans [75].

\section{Summary of Evidence}

Table 2 presents a summary of the studies, reviewed and tallied in Table 1, of the effects of social and economic policies for health of low-income populations. Overall, $83 \%$ of the studies we reviewed included outcome measures for mental health; $83 \%$ included physical health; $72 \%$ included health care, and $50 \%$ included substance use. Among studies that measured those outcomes, $53 \%$ of studies found benefits of the social/economic policy on mental health, and $53 \%$ found benefits on physical health; while effects for substance use and health care were fewer ( $33 \%$ and $31 \%$ respectively). Overall, $72 \%$ of the studies found beneficial health or health care effects of a social or economic policy.

Table 2 Summary of literature review studies of the effects of social and economic policies on health outcomes

\begin{tabular}{|c|c|c|c|c|c|c|c|c|c|c|}
\hline & \multicolumn{2}{|c|}{$\begin{array}{l}\text { Total (any health } \\
\text { outcome) }\end{array}$} & \multicolumn{2}{|c|}{ Mental health } & \multicolumn{2}{|c|}{ Physical health } & \multicolumn{2}{|c|}{ Substance use } & \multicolumn{2}{|c|}{ Health care } \\
\hline & Number & Percent & Number & Percent & Number & Percent & Number & Percent & Number & Percent \\
\hline Studies measuring health outcomes specified & 18 & $100 \%$ & 15 & $83 \%$ & 15 & $83 \%$ & 9 & $50 \%$ & 13 & $72 \%$ \\
\hline Studies documenting health benefits of a policy & 13 & $72 \%$ & 8 & $53 \%$ & 8 & $53 \%$ & 3 & $33 \%$ & 4 & $31 \%$ \\
\hline
\end{tabular}




\section{Conclusions and Implications}

At the core of population health and public health is the assumption that it is necessary to intervene and improve health. The vast majority of social determinants of health and social epidemiology evidence to date is mostly descriptive. The next generation of social epidemiology researchers must therefore pursue intervention to improve health. Reviews of current evidence are necessary to guide intervention. However, the field may be hampered by limited evidence on effective social policies that may improve population health.

In this article, we examined predominantly experimental social policy evaluations among low income populations to assess whether social determinants of health, such as housing subsidies, employment, relationship strengthening/marriage, or income supplementation, may be causes of health outcomes. These evaluations have several general limitations. First, health was not part of the studies' logic models or design. Health was not always proactively addressed in the programs as an issue (e.g., a mediator) that could affect attainment of the main program outcomes (e.g., economic self-sufficiency, for TANF). Second, direct health interventions were not always tested vis-à-vis the program components that addressed SDH. Therefore, these studies do not inform the effectiveness of direct health interventions compared to the effectiveness of interventions that address SDH. Third, the measurement of health outcomes was limited.

There were some social policies corresponding to important social determinants of health for which we found no rigorous studies documenting health evidence. For example, education is an important social determinant of health, and is a major policy domain in and of itself. There is also a large observational body of literature linking education to health outcomes. However, no systematic reviews have been conducted to examine effects of education policies on health in developed nations since 2000 [15]. Moreover, strong educational evaluations typically do not measure health as an outcome [79]. Immigration and immigrant integration are also important social determinants of health with little policy evidence on health outcomes. However, leveraging migration lotteries may be one way to study effects of immigration policies [80]. There were also no strong studies documenting health effects of urban renewal in the USA [20].

Despite these limitations, the evaluations we reviewed provide some evidence on a variety of adult health outcomes. In our review, the majority of policies tended to have beneficial effects on adult mental health and/or physical health (beneficial effects in $53 \%$ of studies that tested for both mental and physical health outcomes). For example, the MTO, HOPWA, NEW Hope, BSF and SHM family strengthening initiatives, and Indian Reservation Gaming income supplements all benefited mental health. Notably, however, we found the health effects faded across time for some policies
(BSF, New Hope). Although social and economic policies also benefited physical health, measures were much more heterogeneous than mental health measures. Health care and substance use were less likely to be affected by these policies. Our findings align with those from one recent literature review, which examined effects of macro-social gender equality policies on gender inequalities in health or on women's health, by leveraging cross-country comparisons. This study found that social policies aiding women (e.g., maternity leave policy), or stricter enforcement of policies such as reproductive policies, were associated with improved mental health and maternal health [81].

The lack of clear patterns across policy evaluations that we found may be due to variation in the targeted populations, the SDH addressed, and/or the measurement of health outcomes. Therefore, there is need for more rigorous research proactively conceived to assess the health effects of social policies. Below we discuss how our review of the existing evidence can inform better health-related social policy (and evaluations).

Implications of Gender Segregation for Program Components

Because of policy design and eligibility, the gender and family structure compositions of the different social policy populations were very different. For example, TANF targets children and their caregivers, and requires that caregivers are single and do not live with partners, which means that TANF recipients of income support are overwhelming single mothers. On the other hand, TANF-funded family strengthening programs primarily target low-income couples. Other programs (particularly in housing) target specific subgroups such as veterans, who are predominantly male.

One important aspect of gender segregation of social policies is gender differences in supports for parenting. Men are not recognized as fathers, and their needs are often addressed as individual needs, not as their needs as family members. In contrast, women in means-tested programs are almost always defined as mothers, with supports for their caregiving role, and their children explicitly considered, in intervention components (for example, child care in welfare to work programs) [82].

These social policies also differentially integrate health services. The programs targeting men (VASH; HOPWA; CHHP) included health services because they targeted ill populations. However, health services are generally not included in social policies targeting single mothers, although some programs like New Hope WtW did offer health care subsidies.

However, health needs are pressing among low-income women with children. Evidence from some social policy interventions (such as the housing revitalization program HOPE VI), strongly suggests that some low-income femaleheaded households have a severe burden of chronic health 
conditions [83]. Since health is on the pathway to key outcomes targeted in social policy such as employment and income, it would be prudent to include health services within social programs.

Incorporating Health Outcomes into Social Policy Evaluation: Beyond Health Care

Although we identified and reviewed some studies that have considered health outcomes, the majority of social and economic policy studies rarely consider health and ignore that these programs could indirectly influence health via SDH (such as employment, earnings, educational attainment, income, marriage, or welfare usage). When social policy evaluations did measure health, the measurement of outcomes had limitations. For example, in the Housing Voucher for Welfare Families study mental health was measured by whether someone reported being "worried, tense, anxious for at least one month in past year" [34,35], which is not a validated measure [84].

It is important for studies to not only integrate validated measures, but also to analyze them according to accepted validated practices established in the health literature. For example, the multi-item K6 psychological distress scale should be analyzed with latent variable item response theory (IRT) techniques [85, 86]. If these techniques are not applied, estimates will be biased towards the null, as occurred in MTO [84].

Another problem is that when health is considered in social policy evaluations, it is often in the narrow sense of health care insurance or utilization, not physical and mental health outcomes. The exceptions are programs (e.g., VASH, HOPWA and CHHP) that are enrolling patients with a medical diagnosis.

However, for programs without explicit diagnostic criteria for program eligibility, program designers should consider which health outcomes might be affected by the program, including both subjective and objective measures. According to our review, mental health is one health domain we recommend evaluating. Short continuous measures like psychological distress (K6), or a short CES-D measure, are appropriate for assessing population health in the general community, and may have better properties in a community sample than gold-standard diagnostic measures [87]. Although many of our included studies did not use biomarkers to measure physical health, valid global health scales like the SF-36 were used to provide an overview of health, including physical and mental health subscales. Some studies also used survey questions on prevalence of specific health conditions (e.g., asthma, diabetes). Such self-reported survey-based health measures are certainly easier and less expensive to obtain than biologic samples [88]. However, when feasible, social policy studies should consider inclusion of biomarkers of subclinical biological processes for common diseases (e.g., precursors of cardiovascular disease) [23]. Biomarkers are not subject to response bias or even to awareness of conditions which may differ by recency of diagnosis, utilization of medical care, or symptomatology. Indeed, MTO found effects of Section 8 rehousing on biomarkers of diabetes and inflammation, but not for survey-based measures [25•*]. Linkage of program records with medical (e.g., Medicaid) records may be another potential option to include diagnostic information and medical history.

\section{Treatment Components}

Social determinants that are manipulated in a social experiment may be very specific and may be limited temporally. As a result they may not correspond to broader, longer-term social determinants, which may be more difficult to change. For example, compare the provision of an income supplement for one year versus income accumulated across the life course. Also, depending on one's developmental period, effects may be very different for a short-duration social determinant, compared to a lifetime of exposure, which may be better captured in an observational social determinant of health study than in a RCT [89]. Effects of some SDH (e.g., income) may also differ, depending on the source. For example, receiving additional income via tax credits may be more socially acceptable, and yield more positive health impacts than that of a governmental benefit (e.g. TANF/welfare use).

Another issue is the potential limited generalizability of findings from experimental studies of social policy, since participants tend to be low-income and thus not representative of the general population. This may limit our ability to understand the effects of SDH across, for example, the full income spectrum. Thus, RCTs of social policy are likely not a good research design for gleaning the entire socioeconomic gradient in health. They are very helpful, however, because they do allow us to understand the effects of key SDH on highly vulnerable populations that disproportionately bear the burden of disease.

\section{Complexities of Identifying the Evidence}

The domains in which systematic reviews have been conducted on social policy effects on health, with the best evidence, include housing mobility policy. Evidence from welfare to work employment programs, income supplementation studies, and family strengthening initiatives is more fragmented. As others have noted, the search to find studies on public health interventions in general may be difficult or time consuming [90]. This difficulty is pronounced when considering 
studies that have examined health effects or health inequalities resulting from social policies aligned with social determinants of health [90]. Search difficulty is driven by the multiple sectors and/or disciplines in which this evidence may be documented [91]. Using disciplinary or content experts to guide the search or indeed, to coauthor a review (as we have done here), may be necessary for identifying literature not found through systematic searches of electronic databases, including studies found in the "grey" literature, or in special journal issues devoted to the topic $[90,91]$.

\section{Conclusion}

In this article, we have reviewed evidence of the health effects of four types of social policies (housing vouchers, welfare to work employment, marriage/family strengthening, and income supplementation), targeting mainly lowincome populations, operating via social determinants of health. We found that many social policies did not evaluate health with comprehensive measures, and that these social policies tended to be segregated by gender in their eligible populations. The main domains of health influenced by these policies seemed to have been improved adult mental and physical health, even though some effects faded with time. Social policies may therefore influence health, even if unintended by policy designers. Ultimately understanding whether and why these policies impact health may inform design of more effective programs, and inform the most important pathways by which social conditions influence health.

Acknowledgements We sincerely thank the WK Kellogg Foundation for supporting this work. The authors would like to thank Dr. Sandro Galea of Columbia University (New York, USA) for his review of the manuscript.

\section{Compliance with Ethics Guidelines}

Conflict of Interest TL Osypuk has received research support from NIH grants, WK Kellogg Foundation, and the Robert Wood Johnson Foundation.

P Joshi has received research support from the WK Kellogg Foundation.

$\mathrm{K}$ Geronimo has received research support from the WK Kellogg Foundation.

D Acevedo-Garcia has received research support from the WK Kel$\log$ Foundation.

Human and Animal Rights and Informed Consent All studies by Dr. Osypuk and Dr. Acevedo-Garcia involving human subjects were performed after approval by the appropriate institutional review boards. When required, written informed consent was obtained from all participants.

\section{References}

Papers of particular interest, published recently, have been highlighted as:

- Of importance

-. Of major importance

1. Commission on Social Determinants of Health. Closing the gap in a generation: health equity through action on the social determinants of health. Geneva: World Health Organisation; 2008.

2. Robert Wood Johnson Foundation Commission to Build a Healthier America. Resources: Social determinants of health. Princeton, NJ: Robert Wood Johnson Foundation, no date: 2.

3. Wilkinson RG, Marmot M. Social determinants of health: the solid facts. 2nd ed. Copenhagen: World Health Organization; 2003.

4. Acevedo-Garcia D, Osypuk TL, McArdle N, Williams D. Toward a policy-relevant analysis of geographic and racial/ethnic disparities in child health. Health Aff. 2008;27(2):321-33.

5. Schoeni RF, House JS, Kaplan GA, Pollack H. Making Americans healthier: social and economic policy as health policy. New York: Russell Sage; 2008.

6. Berkman L, Kawachi I. Social epidemiology. New York: Oxford University Press; 2000.

7. Bardach E. A practical guide for policy analysis: the eightfold path to more effective problem solving. Washington, D.C.: CQ Press; 2009.

8. Weimer DL, Vining AR. Policy analysis: concepts and practice. Upper Saddle River: Prentice Hall; 1999.

9. Stone D. Reframing the racial disparities issue for state governments. J Health Polit Policy Law. 2006;31(1):127-52.

10. Stone DA. Policy paradox: the art of political decision making. New York: Norton; 2001.

11. Robert Wood Johnson Foundation Commission to Build a Healthier America. Beyond health care: new directions to a healthier America: recommendations from the Robert Wood Johnson Foundation Commission to Build a Healthier America. Princeton: Robert Wood Johnson Foundation; 2009.

12. Connor J, Rodgers A, Priest P. Randomised studies of income supplementation: a lost opportunity to assess health outcomes. J Epidemiol Community Health. 1999;53(11):725-30.

13. Ludbrook A, Porter K. Do interventions to increase income improve the health of the poor in developed economies and are such policies cost effective? Appl Health Econ Health Pol. 2004;3(2): 115-20.

14. Ganann R, Ciliska D, Thomas H. Expediting systematic reviews: methods and implications of rapid reviews. Implement Sci. 2010;5(1):56.

15. Bambra C, Gibson M, Sowden A, Wright K, Whitehead M, Petticrew M. Tackling the wider social determinants of health and health inequalities: evidence from systematic reviews. J Epidemiol Community Health. 2010;64(4):284-91.

16. National Low Income Housing Coalition. Federal Budget \& Approps, HUD Budget Charts, FY11 and FY12 Budget Chart for Selected HUD Programs, Updated April 27, 2011. Washington DC. 2011. https://www2398.ssldomain.com/nlihc/template/page.cfm? id=28, http://www.nlihc.org/doc/FY11_12_Budget_Chart_HUD. pdf. Accessed 29 Apr 2011.

17. Sard B. Housing vouchers should be a major component of future housing policy for the lowest income families. In: Wachter SM, Penne RL, editors. Housing policy in the new millennium, Vol. 1. Washington DC: U.S. Department of Housing and Urban Development; 2000. p. 289-318.

18. Leventhal T, Newman S. Housing and child development. Child Youth Serv Rev. 2010;32(9):1165-74. 
19. Acevedo-Garcia D, Osypuk TL, Werbel RE, Meara ER, Cutler DM, Berkman LF. Does housing mobility policy improve health? Hous Pol Debate. 2004;15(1):49-98.

20. Lindberg R, Shenassa E, Acevedo-Garcia D, Popkin S, Villaveces A, Morley RL. Housing interventions at the neighborhood level and health: a review of the evidence. J Publ Health Manag Pract. 2010;16(5 E-Supplement):S44-52.

21. US Department of Housing \& Urban Development. Expanding housing choices for HUD-assisted families: moving to opportunity. First Biennial Report to Congress, Moving to Opportunity for Fair Housing Demonstration Program; 1996.

22. Feins JD, McInnis D. The interim impact evaluation for the moving to opportunity demonstration, C-OPC-21484. Cambridge: Abt Associates Inc; 2001.

23. Ludwig J, Sanbonmatsu L, Gennetian L, Adam E, Duncan GJ, Katz LF, et al. Neighborhoods, obesity, and diabetes: a randomized social experiment. N Engl J Med. 2011;365(16):1509-19.

24. Orr L, Feins JD, Jacob R, Beecroft E, Sanbonmatsu L, Katz LF, et al. Moving to opportunity for fair housing demonstration program: interim impacts evaluation. Washington, DC: US Dept of HUD; 2003. p. 341.

25.• Sanbonmatsu L, Ludwig J, Katz LF, Gennetian LA, Duncan GJ, Kessler RC, et al. Moving to opportunity for fair housing demonstration program: final impacts evaluation. Washington DC: U.S. Department of Housing and Urban Development Office of Policy Development \& Research; 2011. http://www.huduser.org/portal/ publications/pubasst/MTOFHD.html. Reports the long-term health effects of the Moving to Opportunity housing voucher experiment on low-income families up to 15 years following random assignment. Because it is an experiment, this study has an excellent design for understanding the causes of the housing voucher on health and other outcomes. Not only did the treatment group who received the housing voucher subsidy report better neighborhood poverty than controls 10-15 years after baseline, but they also exhibited significantly better mental health, and better physical health outcomes which were not self-reported, such as for biomarkers measuring uncontrolled diabetes, c-reactive protein, and obesity.

26. Goering J, Feins J. Choosing a Better Life? Evaluating the moving to opportunity social experiment. Washington, DC: The Urban Institute Press; 2003.

27. Kling JR, Liebman JB, Katz LF. Experimental analysis of neighborhood effects. Econometrica. 2007;75(1):83-119.

28. Rosenheck R, Kasprow W, Frisman L, Liu-Mares W. Costeffectiveness of supported housing for homeless persons with mental illness. Arch Gen Psychiatry. 2003;60(9):940-51.

29. O'Connell MJ, Kasprow W, Rosenheck RA. Rates and risk factors for homelessness after successful housing in a sample of formerly homeless veterans. Psychiatr Serv. 2008;59(3):268-75.

30. Cheng A-L, Lin H, Kasprow W, Rosenheck RA. Impact of supported housing on clinical outcomes analysis of a randomized trial using multiple imputation technique. J Nerv Ment Dis. 2007;195(1):83-8.

31. Wolitski RJ, Kidder DP, Pals SL, Royal S, Aidala A, Stall R, et al. Randomized trial of the effects of housing assistance on the health and risk behaviors of homeless and unstably housed people living with HIV. AIDS Behav. 2010;14(3):493-503.

32. Sadowski LS, Kee RA, VanderWeele TJ, Buchanan D. Effect of a housing and case management program on emergency department visits and hospitalizations among chronically ill homeless adults: a randomized trial. JAMA. 2009;301(17):1771-8.

33. Buchanan D, Kee R, Sadowski LS, Garcia D. The health impact of supportive housing for HIV-positive homeless patients: a randomized controlled trial. Am J Public Health. 2009;99(S3):S675-80.

34. Wood M, Turnham J, Mills G. Housing affordability and family well-being: results from the housing voucher evaluation. Hous Pol Debate. 2008;19(2):367-412.
35. Abt Associates I, Mills G, Gubits D, Orr L, Long D, Feins J, et al. Effects of housing vouchers on welfare families. Cambridge: U.S. Department of Housing and Urban Development, Office of Policy Development and Research; 2006.

36. Auspos P, Kubisch AC. Building knowledge about community change: moving beyond evaluations. Roundtable on Community Change: The Aspin Institute. 2004. Retrieved from: http://www. aspeninstitute.org/sites/default/files/content/docs/rcc/ BUILDINGKNOWELDGE.pdf

37. DeLuca S, Rosenblatt P. Sandtown-Winchester-Baltimore's daring experiment in urban renewal: 20 years later, what are the lessons learned? Abell Rep. 2013;26(8):1-12.

38. Thomson H, Petticrew M, Morrison D. Health effects of housing improvement: systematic review of intervention studies. BMJ. 2001;323:187-90.

39. Thomson H, Atkinson R, Petticrew M, Kearns A. Do urban regeneration programmes improve public health and reduce health inequalities? A synthesis of the evidence from UK policy and practice (1980-2004). J Epidemiol Community Health. 2006;60(2):108-15.

40. Thomson H, Thomas S, Sellström E, Petticrew M. Housing improvements for health and associated socio-economic outcomes: a systematic review. Cochrane Database Syst Rev. 2013;2, CD008657.

41. Bitler MP, Hoynes HW. Welfare reform and indirect impacts on health. National Poverty Center Working Paper Series: National Poverty Center, Gerald R. Ford School of Public Policy, University of Michigan; 2006.

42. Olson K, Pavetti L. Personal and family challenges to the successful transition from welfare to work. The Urban Institute, Washington, D.C. 1996. Retrieved from http://www.urban.org/publications/ 406850.html.

43. U.S. General Accounting Office. Welfare reform: More coordinated federal effort could help states and localities move TANF recipients with impairments toward employment (GAO-02-37). Washington, D.C. 2001. Retrieved from http://www.gao.gov/new.items/d0237. pdf.

44. Pavetti L, Blank R, Copeland W. Addressing the needs of TANF recipients with disabilities: Opportunities within and outside of TANF. In: Stapleton D, editor. Center for Studying Disability Policy, 2009. http://www.disabilitypolicyresearch.org/forums/ 20090115/Forum 3 transcript.pdf Disability Policy Forum \#3. January $15,2009$.

45. Bitler MP, Gelbach JB, Hoynes HW. Welfare reform and health. J Hum Resour. 2005;40(2):309-34.

46. Kaestner R, Tarlov E. Changes in the welfare caseload and the health of low-educated mothers. J Pol Anal Manag. 2006;25(3): 623-43.

47. Gueron JM, Rolston H. Fighting for reliable evidence. New York: Russell Sage; 2013.

48. Hamilton G, Freedman S, Gennetian L, Michalopoulos C, Walter J, Adams-Ciardullo D, et al. How effective are different welfare-towork approaches? Five-year adult and child impacts for eleven programs. National Evaluation of Welfare-to-Work Strategies. New York: Manpower Demonstration Research Corporation and Child Trends; 2001.

49. McGroder SM, Zaslow MJ, Moore KA, LeMenestrel S. Impacts on young children and their families two years after enrollment: findings from the child outcomes study. National Evaluation of Welfare-to-Work Strategies Report. Washington, DC: U.S. Department of Health and Human Services, Office of the Assistant Secretary; 2000.

50. Hamilton G. Moving people from welfare to work: lessons from the national evaluation of welfare-to-work strategies. Washington, D.C: U.S. Department of Health and Human Services, Administration for Children and Families, Office of the Assistant Secretary for Planning and Evaluation, U.S. Department of Education, Office 
of the Under Secretary, Office of Vocational and Adult Education; 2002.

51. Michalopoulos C, Schwartz C, Adams-Ciardullo D, Manpower Demonstration Research Corporation. National Evaluation of Welfare-to-Work Strategies. What works best for whom: impacts of 20 welfare-to-work programs by subgroup. Washington DC: U.S. Department of Health and Human Services, Administration for Children and Families, Office of the Assistant Secretary for Planning and Evaluation and U.S. Department of Education, Office of the Under Secretary, Office of Vocational and Adult Education; 2001.

52. Morris PA, Huston AC, Duncan GJ, Crosby DA, Bos JM. How welfare and work policies affect children: a synthesis of research. New York: Manpower Demonstration Research Corporation; 2001

53. Alderson DP, Gennetian LA, Dowsett CJ, Imes A, Huston AC. Effects of employment-based programs on families by prior levels of disadvantage. Soc Serv Rev. 2008;82(3):361-94.

54. Miller C, Huston AC, Duncan GJ, McLoyd VC, Weisner TS. New Hope for the working poor: effects after eight years for families and children. New York: MDRC; 2008.

55. Huston AC, Duncan GJ, Granger R, Bos J, McLoyd V, Mistry R, et al. Work-based antipoverty programs for parents can enhance the school performance and social behavior of children. Child Dev. 2001;72(1):318-36.

56. Brock T, Doolittle F, Fellerath V, Wiseman M. Creating New Hope: implementation of a program to reduce poverty and reform welfare. New York: Manpower Demonstration Research Corporation; 1997.

57. Huston AC, Miller C, Richburg-Hayes L, Duncan G, Eldred C, Weisner TS, et al. New Hope for families and children: five-year results of a program to reduce poverty and reform welfare. New York: MDRC; 2003.

58. Huston AC, Gupta AE, Bentley AC, Dowsett C, Ware A, Epps SR. New Hope's effects on social behavior, parenting and activities at eight years (an MDRC working paper). New York: MDRC; 2008.

59. Orth DA, Goggin ML. How states and counties have responded to the family policy goals of welfare reform. Report to the U.S. Department of Health and Human Services, Administration for Children and Families, Grant No. 90XP0028/01. Albany, NY: The Nelson A. Rockefeller Institute of Government, State University of New York. 2003. http://www.rockinst.org/pdf/workforce_welfare and_social_services/2003-12-how_states_and_counties_have responded_to_the_family_policy_goals_of_welfare_reform.pdf

60. McLanahan $\overline{\mathrm{S}}$, Haskins R, Garfinkel $\overline{\mathrm{I}}$, Mincy RB, Donahue E. Strengthening fragile families. Princeton: Future of Children; 2010.

61. Wood RG, McConnell S, Moore Q, Clarkwest A, Hsueh J. The effects of building strong families: a healthy marriage and relationship skills education program for unmarried parents. J Pol Anal Manag 2012;31(2):242-45.

62. Wood RG, Moore Q, Clarkwest A, Killewald A, Monahan S. The long-term effects of building strong families: a relationship skills education program for unmarried parents. Final Report OPRE Report 2012-28A. Washington DC: Office of Planning, Research and Evaluation, Administration for Children and Families, U.S. Department of Health and Human Services (OPRE). 2012. http:// www.acf.hhs.gov/sites/default/files/opre/bsf_36_mo_impact_ report.pdf.

63. Moore Q, Wood RG, Clarkwest A, Killewald A, Monahan, S. The long-term effects of Building Strong Families: A relationship skills education program for unmarried parents. Technical supplement, OPRE Report 2012-28C. Washington, DC: Office of Planning, Research and Evaluation, Administration for Children and Families, U.S. Department of Health and Human Services (OPRE). 2012, p. A-12.

64. Wood RC, McConnell S, Moore Q, Clarkwest A, Hsueh J. Strengthening unmarried parents' relationships: the early impacts of building strong families. The building strong families project. Princeton: Mathematica Policy Research, Inc; 2010.
65. Hsueh J, Alderson DP, Lundquist E, Michalopoulos C, Gubits D, Fein D, et al. The supporting healthy marriage evaluation: early impacts on low-income families. OPRE Report 2012-11 New York NY: Manpower Demonstration Research Corporation, 2012. Presents the 30-month evaluation for the Supporting Healthy Marriage (SHM) program for low income married couples. Given its experimental design, this program offers strong evidence on manipulating relationship quality, which result in benefits for mental health and domestic violence. This is an unusual opportunity to study how changes in romantic relationships within the context of marriage influence health outcomes, with such a strong study design.

66. Fiszbein A, Schady N. Conditional cash transfers: reducing present and future poverty. World Bank Policy Research Report. Washington DC: World Bank; 2009.

67. Riccio JA, Dechausay N, Greenberg DM, Miller C, Rucks Z, Verma N. Toward reduced poverty across generations: early Findings from New York City's Conditional Cash Transfer Program. NY: MDRC; 2010.

68.• Riccio J, Dechausay N, Miller C, Nuñez S, Verma N, Yang E. Conditional cash transfers in New York City: the continuing story of the opportunity NYC-family rewards demonstration. New York: MDRC; 2013. Presents the 3-4 year evaluation for the Opportunity NYC-Family Rewards Demonstration, which documented with an experimental design (thus high validity) how conditional cash transfers (CCTs) led to better dental care and nutritional benefits among low-income families, compared to controls. Although CCTs are popular and effective in developing countries to disrupt the intergenerational effects of poverty on human capital (health and education), this was the first conditional cash transfer program to be implemented in a developing nation.

69. Pega F, Carter K, Blakely T, Lucas PJ. In-work tax credits for families and their impact on health status in adults. Cochrane Database Syst Rev. 2013;6(8), CD009963. Presents a Cochrane systematic review on the health effects of Earned Income Tax Credits (EITC) (known as In-Work Tax Credits outside the U.S.) among working-aged adults. This is a comprehensive review of evidence, with very detailed multidimensional analysis of empirical studies on the topic. Although few studies were ultimately captured by the review, this manuscript provides excellent discussion on the methodological issues of evaluating with observational methods this large, long-running, efficient tax policy that lifts millions of low-income households out of poverty.

70. McCarrier KP, Zimmerman FJ, Ralston JD, Martin DP. Associations between minimum wage policy and access to health care: evidence from the behavioral risk factor surveillance system, 1996-2007. Am J Public Health. 2011;101(2):359-67.

71. Meltzer DO, Chen $Z$. The impact of minimum wage rates on body weight in the united states. In: National Bureau of Economic Research, editor. Cambridge, MA: NBER WORKING PAPER SERIES; 2009. Working Paper 15485 http://www.nber.org/papers/w15485.

72. Sabia JJ, Nielsen RB. Can raising the minimum wage hardship? New evidence from the survey of income and program participation. Washington DC: Employment Policies Institute; 2010.

73. Gueron JM, Rolston H. Chapter 1. Introduction: the issue, the method, and the story in brief. In: Gueron JM, Rolston H, editors. Fighting for reliable evidence. New York: Russell Sage Foundation; 2013. p. 1-21.

74. National Indian Gaming Association. The economic impact of Indian gaming. Washington: National Indian Gaming Association; 2009. http://www.indiangaming.org/info/NIGA_2009_Economic Impact_Report.pdf.

75. Momper SL. Implications of American Indian gambling for social work research and practice. Soc Work. 2010;55(2):139-46.

76. Costello E, Compton SN, Keeler G, Angold A. Relationships between poverty and psychopathology: a natural experiment. JAMA. 2003;290(15):2023-9. 
77. Costello E, Erkanli A, Copeland W, Angold A. Association of family income supplements in adolescence with development of psychiatric and substance use disorders in adulthood among an american indian population. JAMA. 2010;303(19):1954-60.

78. Wolfe B, Jakubowski J, Haveman R, Courey M. The income and health effects of tribal casino gaming on American Indians. Demography. 2012;49(2):499-524.

79. U. S. Department of Education. What works clearinghouse at the US Department of Education. 2013. http://whatworks.ed.gov. Accessed 30 Oct 2013.

80. Stillman S, Gibson J, McKenzie D. The impact of immigration on child health: experimental evidence from a migration lottery program. Econ Inq. 2012;50(1):62-81.

81. Borrell C, Palència L, Muntaner C, Urquía M, Malmusi D, O'Campo P. Influence of macrosocial policies on women's health and gender inequalities in health. Epidemiol Rev. 2014;36(1):3148.

82. Gennetian LA, Huston AC, Crosby DA, Chang YE, Lowe ED, Weisner TS. Making child care choices: how welfare and work policies influence parents' decisions. MDRC Policy Brief. New York: Manpower Demonstration Research Corporation; 2002.

83. Manjarrez CA, Popkin SJ, Guernsey E. Poor health: adding insult to injury for HOPE VI Families. Metropolitan Housing and Communities Center. Washington DC: The Urban Institute; 2007.

84. Osypuk TL, Tchetgen Tchetgen EJ, Acevedo-Garcia D, Earls FJ, Lincoln AK, Schmidt NM, et al. Differential mental health effects of neighborhood relocation among youth in vulnerable families: results from a randomized trial. Arch Gen Psychiatry. 2012;69(12): 1284-94.

85. Kessler R, Andrews G, Colpe L, Hiripi E, Mroczek D, Normand S, et al. Short screening scales to monitor population prevalences and trends in non-specific psychological distress. Psychol Med. 2002;32(06):959-76.

86. Reeve BB, Hays RD, Chang C-H, Perfetto EM. Applying item response theory to enhance health outcomes assessment. Qual Life Res. 2007;16(Supplement 1):1-3.

87. McMahon SD, Grant KE, Compas BE, Thurm AE, Ey S. Stress and psychopathology in children and adolescents: is there evidence of specificity? J Child Psychol Psychiatry. 2003;44(1):107-33.

88. Gwynn RC, Garg RK, Kerker BD, Frieden TR, Thorpe LE. Contributions of a local health examination survey to the surveillance of chronic and infectious diseases in New York City. Am J Public Health. 2009;99(1):152-9.

89. Berkman LF. Social Epidemiology: Social determinants of health in the united states: are we losing ground? Annu Rev Public Health. 2009;30(1):27-41.

90. Jackson N, Waters E, the Guidelines for Systematic Reviews of Health Promotion Public Health Interventions Taskforce. The challenges of systematically reviewing public health interventions. J Publ Health. 2004;26(3):303-7.

91. Ogilvie D, Hamilton V, Egan M, Petticrew M. Systematic reviews of health effects of social interventions: 1. Finding the evidence: how far should you go? J Epidemiol Community Health. 2005;59(9):804-8. 